\title{
Phenoxybenzamine Hydrochloride
}

National Cancer Institute

\section{Source}

National Cancer Institute. Phenoxybenzamine Hydrochloride. NCI Thesaurus. Code C44435.

The hydrochloride salt form of phenoxybenzamine, a synthetic, dibenzamine alphaadrenergic antagonist with antihypertensive and vasodilatory properties.

Phenoxybenzamine non-selectively and irreversibly blocks the postsynaptic alphaadrenergic receptor in smooth muscle, thereby preventing vasoconstriction, relieving vasospasms, and decreasing peripheral resistance. Reflex tachycardia may occur and may be enhanced by blockade of alpha-2 receptors which enhances norepinephrine release. Phenoxybenzamine is reasonably anticipated to be a human carcinogen. 